\title{
FORMAÇÃO DE LEITORES LITERÁRIOS NA AMAZÔNIA BRASILEIRA: DA ESCUTA À LEITURA SILENCIOSA
}

FORMATION OF LITERARY READERS IN BRAZILIAN AMAZON: FROM LISTENING TO SILENT READING

Andréia dos Santos Oliveira'

1 Doutoranda em Educação pela Universidade Estadual Paulista "Júlio de Mesquita Filho", campus Marília. Professora de Língua Portuguesa do Instituto Federal de Rondônia. E-mail: andreia. oliveira@ifro.edu.br 
RESUMO: Por compreender a leitura como direito fundamental da humanidade, tenho desenvolvido projetos que garantam o acesso de crianças aos textos literários. $\mathrm{O}$ artigo em tela objetiva relatar duas dessas ações extensionistas desenvolvidas em dois projetos de leitura, cujo objetivo central foi contribuir com a formação de leitores literários em duas cidades do estado de Rondônia, Amazônia brasileira. As ações ocorreram a partir da problematização: Como garantir o acesso aos textos literários ao maior número possível de crianças fora do ambiente escolar? Para isso, recorri à leitura de autores cujos argumentos se dão em defesa da necessidade do contato das crianças pequenas com o texto literário, a exemplo de Candido (2004), Bajard (1994, 2014), Arena e Arena (2015), Lima e Girotto (2015), Petit (2010), entre outros. Em seguida, elaborei e desenvolvi duas ações extensionistas. Os resultados apontam a importância de mediadores de leitura promovendo a interação entre a criança e o livro, por meio da escuta e da leitura silenciosa.

PALAVRAS-CHAVE: Projeto de extensão; Formação de leitores; Escuta; Leitura silenciosa.

ABSTRACT: Because I understand reading as a fundamental right of humanity, I have developed projects that guarantee children's access to literary texts. The article in question aims to report two of these extension actions developed in two reading projects whose central objective was to contribute to the formation of literary readers in two cities in the state of Rondônia, Brazilian Amazon. The actions took place from the problematization: How to guarantee access to literary texts to the largest possible number of children outside the school environment? For this, I resorted to reading authors whose arguments are in defense of the need for small children to have contact with the literary text, such as Candido (2004), Bajard (1994, 2014), Arena and Arena (2015), Lima and Girotto (2015), Petit (2010) among others. Then, I elaborated and developed two extension actions. The results point to the importance of reading mediators promoting the interaction between the child and the book through listening and silent reading.

KEYWORDS: Extension Project; Formation of literary readers; Listening. Silent reading. 


\section{INTRODUÇÃO}

Antonio Candido, em seu escrito $O$ direito à literatura, defende o acesso aos textos literários como direito universal da humanidade. Segundo o autor, todo homem precisa, de alguma forma, manter o contato com a ficção.

Vista deste modo, a literatura aparece claramente como manifestação universal de todos os homens, em todos os tempos. Não há povo e não há homem que possa viver sem ela, isto é, sem a possibilidade de entrar em contato com alguma espécie de fabulação. Assim como todos sonham todas as noites, ninguém é capaz de passar as vinte $\mathrm{e}$ quatro horas do dia sem alguns momentos de entrega ao universo fabulado. (CANDIDO, 2004, p. 174).

Assim, como é necessário o pão para alimentar o corpo, recorre-se às fabulações como alimento da alma. Portanto, uma das formas de garantir esse direito é promovendo a formação de leitores literários.

A pesquisadora francesa Michèle Petit corrobora com a posição de Candido e acrescenta os benefícios da arte literária tanto para a constituição do próprio sujeito quanto para a sua atividade psíquica. Em tempos difíceis “[...] crianças, adolescentes e adultos poderiam redescobrir o papel dessa atividade na reconstrução de si mesmos e, além disso, a contribuição única da literatura e da arte para a atividade psíquica”. (PETIT)

Além disso, ambos defendem a constituição do leitor literário como social, visto que essa formação depende da presença de mediadores de leitura promovendo o contato das crianças com os livros em ambientes de leitura, tais como bibliotecas escolares, públicas e particulares, salas de aulas, salas de leituras, entre outras. Toda a sociedade, desde a família, professores, bibliotecários devem criar condições para essa promoção.

Pensando em tal demanda, consciente de que como professora-pesquisadora precisava contribuir nesse processo de formação de leitores, desenvolvi, com a colaboração de alunas e professoras do Instituto Federal de Rondônia, dois projetos de acesso aos textos literários nas cidades de Ariquemes e Porto Velho. Enquanto um almejava levar os livros literários para ambientes públicos, tais como praças, o outro 
pretendia garantir o seu acesso a um grupo de crianças em situação de vulnerabilidade social, moradoras de um lar de acolhimento. Este artigo objetiva relatar as ações desenvolvidas e os resultados alcançados nesses projetos, assim como analisá-los à luz dos teóricos escolhidos para fundamentar as discussões.

\section{A IMPORTÂNCIA DOS MEDIADORES PARA A FORMAÇÃO DE LEITORES LITERÁRIOS}

Não se nasce leitor, forma-se à medida que se vive. $\mathrm{O}$ ato de ler faz parte das conquistas sociais da humanidade, não sendo, portanto, inato ao homem. Por isso, a apropriação dessa prática cultural está relacionada aos estímulos sociais provocados em diferentes ambientes, como defende Mello:

Assim, a presença do livro como objeto cultural no entorno da criança é condição necessária para a formação do ato leitor. No entanto, ainda que necessários, os livros em si não são suficientes para a constituição da necessidade da leitura. É a forma como o professor insere o livro na experiência dos pequenos que pode fazer do ato de ler uma vivência emocional transformadora para a criança. (MELLO, 2016, p.48)

Assim sendo, apesar da importância de permitir o contato da criança pequena com o livro, ele por si só não é suficiente no processo de formação de leitores. A figura dos mediadores de leitura literária, sujeitos mais experientes, é essencial desde os primeiros meses de vida. Entendo como mediador de leitura "[...] a pessoa que se interpõe entre o texto e o receptor, tendo em vista facilitar sua recepção" (BAJARD, 2014, p.45).

Sabendo dessa importância, Bajard (1994) argumenta sobre a necessidade de a Literatura Infantil ocupar espaços privilegiados na vida da criança desde os primeiros meses de vida, tanto em contextos escolares quanto familiares. Proporcionar o contato dos pequenos com os textos literários torna-se fundamental para o desenvolvimento infantil, pois o contato com os livros: 
[...] abre o mundo da língua escrita, ou seja, de uma outra linguagem. À riqueza da língua oral se acrescenta a da língua escrita que, por sua vez, vai participar da educação da pessoa em todas as suas dimensões imaginária, científica, espiritual, cívica, mas também linguageira e cognitiva. (BAJARD, 2014, p. 43).

Também Arena e Arena (2015) corroboram com o argumento de Bajard e explicam que, desde a segunda década do século XXI, a concepção de que é preciso a presença de um adulto, sujeito mais experiente, para inserir a criança no mundo da leitura e da escrita tem aumentado. Isso porque ler é um gesto cultural, construído ao longo do tempo pela humanidade. Portanto, não faz parte das funções elementares humanas, mas de um processo de aprendizagem. Nas palavras dos autores:

[...] o desenvolvimento do indivíduo e suas interações com o outro são necessárias e fundamentais, porque delas são criados os signos, os gêneros do discurso - entre eles, a literatura infantil, portadora de cultura - e a criação da apreciação estética (ARENA; ARENA, 2015, p.459).

Dessa forma, é preciso que esses mediadores tenham conhecimento das formas possíveis de proporcionar o contato das crianças com as narrativas literárias. Entre os vários requisitos necessários aos mediadores de leitura literária, Lima e Girotto destacam:

Consideramos que a mediação da leitura acontece por sujeitos que leem, discutem e promovem um diálogo entre texto e leitor. Tais sujeitos podem ser elencados como pais que leem para os filhos em voz alta ou compram livros para a biblioteca doméstica; professore(a) s que trabalham com práticas de leitura, nas escolas; bibliotecários que atualizam acervos e promovem programas de leitura, nas bibliotecas públicas e particulares, dentre outros. (LIMA; GIROTTO, 2015, p. 54).

Todos esses mediadores citados pelas professoras-pesquisadoras têm papel essencial no processo de formação de leitores. À família cabe, desde muito cedo, apresentar os livros às crianças, seja por meio da prática cultural que envolve a oralidade, 
seja pela disponibilização de livros ilustrados para os primeiros contatos individuais e silenciosos dos pequenos com o texto narrado por meio de dois códigos: o verbal e o não-verbal. Já “[...] a escola e seus agentes são responsáveis pelo ensino da prática cultural do ato de ler e, para isso, não basta ensinar o domínio do sistema linguístico, porque esse não é, especificamente, o objeto a ser ensinado" (ARENA, 2015, p.136). É preciso ensinar aos pequenos os modos culturais de ler.

Mas, se a escola tem a função de ensinar o ato cultural de ler, a família tem o papel de apresentar os livros às crianças desde que elas nascem, como garante Petit (2010, p.22). Segundo ela: "Na maioria das vezes, tornamo-nos leitores porque vimos nossa mãe ou nosso pai mergulhados nos livros quando éramos pequenos, porque os ouvimos ler histórias ou porque as obras que tínhamos em casa eram tema de conversa". Entretanto, infelizmente, nem todas as crianças nascem em um lar cujo ambiente de leitura é ideal. E isso ocorre por distintas razões: há famílias com boas condições financeiras, mas que não consideram a leitura um valor, ou algo que seja de sua competência; há outras que valorizam a leitura, entretanto não podem comprar os livros. Essa realidade não é rara e nem exclusividade do Brasil. Petit tem percorrido o mundo com seus projetos de formação de leitores e chegou à seguinte conclusão:

Quando se vive em bairros pobres na periferia da cidade, ou no campo, os livros são objetos raros, pouco familiares, investidos de poder, que provocam medo. Estão separados deles por verdadeiras fronteiras, visíveis ou invisíveis. E se os livros não vão até eles, eles nunca irão até os livros". (PETIT, 2013, p. 24).

Quando isso ocorre, os pequenos terão acesso ao objeto cultural livro literário apenas quando chegarem à escola. E, nesse ambiente formal de ensino, nem sempre a promoção da leitura ocorre de forma ideal, porque muitas vezes o próprio professor não se constituiu leitor literário, fator essencial a quem pretende atuar como mediador de leitura literária. Em muitas escolas faltam ainda livros literários de qualidade, bibliotecas, bibliotecários e professores com formação adequada para formar leitores. Quando isso ocorre, as crianças ficam abandonadas à própria sorte e as chances de constituírem-se em leitoras literárias diminui drasticamente. 
Foi pensando em todas essas problemáticas identificadas e relatadas na dissertação de mestrado, a qual tinha como objetivo compreender a prática pedagógica envolvendo a leitura literária de professoras dos primeiros anos do Ensino Fundamental (OLIVEIRA, 2015), que me conscientizei da importância social de desenvolver projetos de extensão que contribuíssem com a formação de leitores literários. Os projetos que passo a relatar a partir de agora, apesar de terem o mesmo objetivo, foram desenvolvidos em anos e cidades distintas.

O primeiro projeto denominado Contadores de histórias foi desenvolvido durante o ano de 2016, em uma praça pública do município de Ariquemes, situado a 200 quilômetros da capital de Rondônia, Porto Velho. O projeto constituiu-se como ação de extensão e foi desenvolvido por mim, professora de Língua Portuguesa do Instituto Federal de Rondônia e uma aluna do curso técnico integrado de Informática do campus Ariquemes.

Semanalmente ia até o local escolhido com uma mala, denominada por nós de Mala de leitura viajante, preparava o espaço, tapetes coloridos, almofadas e livros ilustrados, para receber as crianças. O público infantil era formado, em sua maioria, por frequentadores da praça pública. Geralmente essas crianças eram levadas até o local pelos pais para brincarem, porém, com o projeto, viram a possibilidade de o espaço servir também como promotor de leitura. Nesse local, promovia o contato dos pequenos com a narrativa literária por meio de três ações: contação de histórias, transmissão vocal do texto e a leitura silenciosa.

O projeto iniciou-se de forma tímida, com um número reduzido de participantes, mas, com o decorrer do tempo, esse número aumentou e muitos foram os depoimentos dos pais de que as crianças, ao tomarem conhecimento de que todas as quartas-feiras haveria essa ação de extensão, começaram a pedir a eles que as levassem no dia e horário do projeto. A divulgação ficou por conta das próprias crianças que, a cada novo encontro, traziam familiares e amigos. Essa ação ocorreu durante um semestre de 2016.

O segundo projeto, também ação de extensão², foi desenvolvido no ano de 2018

2 Esse projeto foi desenvolvido em um semestre do ano de 2018 e foi registrado como projeto no 
em uma instituição pública que acolhia crianças em situação de vulnerabilidade social. A ação foi desenvolvida por compreender o acesso ao texto literário como direito fundamental da infância. Entretanto, como as crianças, público do projeto, estavam afastadas da família por diferentes motivos, tinham esse direito limitado. Vi, portanto, a possibilidade de, por meio de um projeto de extensão denominado Contando histórias, formando leitores contribuir para o acesso das crianças às narrativas literárias.

Para isso, semanalmente, ia até o abrigo acompanhada de alunas do curso superior de Gestão Pública do Instituto Federal de Rondônia, campus Porto Velho, Zona Norte e de professoras colaboradoras do projeto. Durante uma hora, as crianças tinham contato com os textos por meio da escuta e da leitura silenciosa.

Ambos os projetos tiveram o mesmo tempo de duração semanal e seguiram a mesma ordem no processo de acesso às narrativas literárias. Primeiro por meio da escuta, seja pela contação de histórias ou pela transmissão vocal do texto, em seguida pelo encontro individual com o livro, garantido por meio da leitura silenciosa. A partir de agora, passo a argumentar sobre a necessidade da escuta e sobretudo da leitura silenciosa na formação de leitores e os critérios adotados nas escolhas das obras literárias.

\section{O ACESSO ÀS NARRATIVAS LITERÁRIAS POR MEIO DA ESCUTA: O PROJETO EM AÇÃO}

"Dizer o texto" foi uma das formas utilizadas nos projetos para compartilhar as narrativas literárias com as crianças. No entanto, apesar dessa prática contribuir para a formação de leitores, é preciso distingui-la da prática cultural de ler. Para Bajard (2014) o dizer pode ser definido como sendo o ato de tornar público o texto escrito por meio da voz.

Dizer o texto é ato democrático, já que possibilita o acesso à narrativa literária mesmo por aquelas crianças que ainda não sabem ler convencionalmente. Essa tradi-

Departamento de Extensão do Instituto Federal de Rondônia, campus Porto Velho, Zona Norte. 
ção, além de importante para a formação de leitores, é antiga, diz Bajard (2014), pois era praticada frequentemente por famílias europeias logo após a Reforma Protestante.

$\mathrm{O}$ acesso às narrativas literárias, por meio do dizer, pode ocorrer tanto pela contação de histórias, quanto pela transmissão vocal do texto, explica Bajard (2014). Ambas as formas foram utilizadas nos projetos apresentados neste artigo. Para isso, as sessões de mediações de leitura eram divididas em dois momentos: os primeiros trinta minutos permitiam o acesso das crianças ao texto por meio da escuta e os trinta minutos restantes pela prática da leitura silenciosa.

Considerei importante iniciar as sessões de mediação pela escuta, por considerá-la fundamental no processo de formação de leitores literários, como defende Abramovich :

Ah, como é importante para a formação de qualquer criança, ouvir muitas, muitas histórias. Escutá-las é o início da aprendizagem para ser um leitor, e ser leitor é ter um caminho absolutamente infinito de descoberta e de compreensão do mundo. (ABRAMOVICH,2003, p.16)

Para as crianças, o acesso às narrativas, pela voz de um mediador, chega pela escuta, seja pela transmissão vocal do texto ou contação de histórias. Entretanto, é preciso distinguir esses dois processos, pois, apesar de similares, eles não devem ser confundidos. Enquanto a transmissão vocal [...] reside na transformação, por um locutor, de uma matéria visual em matéria vocal" (BAJARD, 2014, p.30), exigindo, portanto, a presença física do livro, a contação de histórias necessita apenas da voz do narrador.

Ouvir histórias é importante tanto para o processo de formação de leitores literários, quanto para a própria humanização da criança, visto que: "É ouvindo histórias que se pode sentir (também) emoções importantes, como a tristeza, a raiva, a irritação, o bem-estar, o medo, a alegria, o pavor, a insegurança, a tranquilidade, e tantas outras mais [...]" (ABRAMOVICH, 2003, p.17). Além disso, prossegue a autora, por meio de uma narrativa ouvida, a criança pode tanto se redescobrir como descobrir lugares, tempos, modos distintos de ser e agir. Enfim, ampliar a sua visão de si mesma e do mundo, alargar as suas experiências e vivências.

Entretanto, para que o ouvir provoque tantas emoções no pequeno ouvinte, é preciso planejamento do mediador de leitura, pois, antes de dizer um texto literário 
a uma criança, é preciso preparar o momento. E isso tem início na escolha dos livros que serão apresentados aos pequenos. Sobre o processo de escolha, Oliveira, Girotto e Rodrigues (2020, p.98) argumentam:

[...] muitos são os critérios que devem ser analisados, desde a concepção até as características do texto literário infantil, pois este deve ser compreendido como arte constituída de palavras. A concepção de criança compartilhada pelo livro também deve ser considerada, assim como se o que nele está apresentado é coerente com os valores de liberdade e tolerância. Além disso, as suas dimensões material, verbal e não verbal. Aqui é preciso considerar a articulação entre imagem e texto, além das técnicas de ilustração. Compreender as transformações ocorridas na Literatura Infantil também é fundamental.

Por isso, durante toda a execução dos projetos havia um tempo dedicado à escolha dos textos que seriam transmitidos e daqueles que seriam contados. Para a transmissão, optava por aqueles cujas ilustrações eram essenciais à atribuição de sentidos, pois via nesse momento a possibilidade de ensinar as crianças a lerem livros ilustrados. Os enredos das histórias também eram analisados com o intuito de verificar se eram coerentes com os princípios de liberdade e tolerância.

No planejamento de ambas as ações, após a escolha do livro, os textos eram lidos e estudados para escolher a melhor maneira de dizê-los às crianças. Abramovich adverte que essa ação não pode ser executada de qualquer maneira, pois:

Para contar uma história - seja qual for- é bom saber como se faz. [...] Contar histórias é uma arte ... e tão linda!!! É ela que equilibra o que é ouvido com o que é sentido, e por isso não é nem remotamente declamação ou teatro ... Ela é o uso simples e harmônico da voz. (ABRAMOVICH, 2003, p.18)

Durante todas as transmissões vocais, sentava-me diante do grupo, com o livro aberto, direcionado para o público. Isso era feito dessa maneira, porque a escuta de um livro ilustrado não substitui a necessidade de a criança ter acesso às ilustrações. Portanto, pensar em uma posição que permitisse aos pequenos contemplar os enunciados não verbais foi essencial. (BAJARD, 2014). 
A emissão vocal tem relação com o volume, altura, timbre e acento da voz. Ao transmitir um texto, é preciso que o locutor-mediador compreenda as entonações da voz de cada personagem e as pausas necessárias em determinados momentos. É preciso saber o momento de "correr" com o texto e de pronunciá-lo vagarosamente. Abramovich (2003, p. 21) explica: "Ah, é bom saber usar as possibilidades da voz: sussurrar quando a personagem fala baixinho ou está pensando em algo importantérrimo; é bom levantar a voz quando uma algazarra está acontecendo, ou falar de mansinho quando a ação é calma”. E assim fazia em todas as vezes que dizia ou contava os textos às crianças.

Todas as ações foram planejadas de modo a contribuir para que a escuta permitisse experiência estética dos pequenos. Como isso depende da cadência e ritmos do narrador (MACHADO, 2004), utilizei todas as possibilidades da voz. O grito do lobo, o sussurro de um personagem amedrontado foram essenciais para cativar as crianças a participarem das atividades. Os sentimentos despertados por esse uso harmônico da voz eram expressados em seus rostos das mais diversas formas: com risos, gritinhos, expressão de espanto, entre outros.

Sisto e Motoyama (2016, p.112) defendem a necessidade de, durante a contação de histórias, "criar uma atmosfera para que o outro [...] possa tocar a história com seus olhos, sua emoção, sua imaginação, sua memória, sua própria história”, para isso além das várias possibilidades da voz, busquei recursos como fantoches, dedoches e aventais de histórias. Todos esses elementos encantavam as crianças e as mantinham atentas à narrativa. Destaco que, na perspectiva da Teoria histórico-cultural formulada por Vygotsky e colaboradores, a atenção é uma atividade psíquica superior, portanto não é inata ao homem, mas constituída nas relações sociais. Por isso é preciso criar meios para que as crianças se apropriem dela e o ouvir histórias mostrou-se propício para isso, pois, com os enredos que agradavam ao público infantil, com o uso das possibilidades da voz e alguns objetos para auxiliar na contação, as crianças ficavam atentas à escuta do princípio ao fim.

Algumas vezes, antes de iniciar o momento de contação, as crianças estavam agitadas, então buscava formas para que as suas atenções se voltassem ao texto e isso ocorria geralmente por meio de músicas e também apresentando o livro físico, isso 
é essencial mesmo quando a história será contada, pois a criança precisa saber que a narrativa que chega a ela, por meio da oralidade, está presente em um livro físico e, caso ela queira o contato com aquele enredo de forma silenciosa, ela precisará se apropriar dos modos culturais de ler. Além de apresentar a capa da obra com as suas ilustrações, dialogava com as crianças sobre as suas expectativas e inferências para a narrativa. Além disso, criava condições para que elas mobilizassem os seus conhecimentos prévios sobre o assunto, pois isso é fundamental para a atribuição de sentidos ao texto como defendem Girotto e Souza (2010). Também incentivava as crianças a fazerem perguntas para o texto, para que encontrassem as respostas enquanto ouviam a história e assim elas procediam.

Contudo, apesar de saber da contribuição dessas duas ações para a formação de leitores- contar e transmitir o texto - compreendo que elas não se caracterizam como prática cultural de ler. Sobre isso Bajard (1994, p.80) alerta que o dizer, apesar de necessário, não pode substituir a leitura, pois "Cada uma tem a sua função, cada uma exige capacidades específicas, cada uma é uma entrada particular na língua escrita e na cultura".

Assim, com o objetivo de contribuir para o desenvolvimento da "[...] leitura íntima chamada de silenciosa[...]" (BAJARD, 2014, p.18), aproveitei as situações em que os livros estavam presentes para apresentar aos pequenos os modos de lê-los (BAJARD, 2014). Essas experiências envolvendo a leitura silenciosa foram proporcionadas para garantir que as crianças ultrapassassem a “[...]escuta, suscitando também atitudes de leitor" (BAJARD, 2014, p.96). Em todas as sessões de mediações, após os momentos iniciais de dizer o texto, deixava os livros à disposição das crianças para que elas desenvolvessem os gestos embrionários de leitura.

Girotto (2015) defende a importância da criação de gestos embrionários desde muito cedo, pois são eles que futuramente irão constituir a atitude leitora da criança ou até mesmo a sua capacidade de ler.

Como em ambos os projetos havia crianças de distintas faixas etárias e as bem pequeninas não dominavam a leitura dos enunciados verbais, optei por oferecer livros ilustrados, porque nesses, graças à sua composição bilíngue, "[...] a narrativa pode emergir diretamente da imagem, satisfazendo de imediato o leitor iniciante". (BAJARD, 2014, p.58). 
Observei comportamentos distintos praticados pelas crianças que frequentavam as sessões de mediações na praça pública de Ariquemes e por aquelas moradoras da instituição pública de Porto Velho, que acolhia crianças em situação de vulnerabilidade social. Pelas vozes das crianças, foi possível perceber que, enquanto as primeiras, mesmo aquelas que ainda não frequentavam a escola, tinham alguma forma de contato com os textos literários no ambiente familiar, o segundo grupo de crianças, especialmente aquelas bem pequenas, tinham o contato reduzido com os livros literários, visto que antes de entrar na escola, geralmente, esse contato é garantido pela família e essas crianças, pelos diferentes motivos, haviam sido afastadas do convívio familiar. Dessa forma julgo as dificuldades apresentadas por elas, no início do projeto, de se comportarem diante de um livro.

Em todas as sessões, os livros ilustrados eram deixados espalhados sobre um tapete. No início da segunda ação extensionista, muitas eram as crianças pequeninas que os pisoteavam e até rasgavam algumas de suas folhas. Mesmo assim, o contato dos pequenos com os livros não foi limitado, isso porque corroboro com o posicionamento de Jolibert et al. (2006, p.31): “[...] o cuidado e a manutenção dos livros têm de ser objeto de uma aprendizagem [...]" e não de punição. Se o homem se constitui a partir das relações sociais estabelecidas com os outros e com o meio, também o leitor se forma a partir dos contatos com os livros. Assim sendo, acredito que o aprendizado dos modos de ser leitor é conquistado nas experiências coletivas de leitura e nos contatos individuais com o livro.

Com o passar do tempo, à medida que observavam os gestos de leitura utilizados por mim e pelos demais mediadores, as crianças apropriaram-se desse conhecimento e alteraram os modos de se relacionar com os livros. Esses não eram mais rasgados ou pisoteados, mas segurados com cuidado, zelo e atenção. A partir das ilustrações, os pequenos produziam suas próprias narrativas e exteriorizavam-nas pela voz.

Por fim, encerro o artigo declarando que as sessões de mediações foram importantes para a constituição leitora, tanto para o grupo de crianças de Ariquemes, quanto para o de Porto Velho. Entretanto, para essas últimas, o projeto extrapolou o seu objetivo e tornou-se uma forma de contato. Para essas crianças, os livros tornaram-se pontes para o afeto, alegrias e sonhos. 


\section{CONSIDERAÇÕES FINAIS}

Por compreender o acesso à leitura como direito fundamental da infância, desenvolvi os projetos de extensão que contribuíram para a formação de leitores literários por meio da escuta e da leitura silenciosa. Os resultados obtidos atestam a importância dos mediadores para a formação do leitor literário. Ao me interpor entre a criança e o livro, seja por meio das escolhas das obras a serem oferecidas como defendem Oliveira, Girotto e Rodrigues (2020), seja pela voz com as suas distintas possibilidades, como explica Abramovich (2003) ou apresentando a elas os modos culturais de ler defendidos por Bajard (2014), as crianças foram familiarizando-se com os livros e apropriando-se dos modos culturais de lê-los.

Pelos depoimentos das próprias crianças e dos pais que as levavam até a Praça Municipal de Ariquemes, acredito que os projetos tenham contribuído para a constituição das crianças em leitoras literárias. Por seus resultados positivos, defendo que, cada vez mais, família, escola e sociedade em geral devem unir-se em prol de garantir o acesso das crianças aos textos literários de qualidade, pois assim estaremos todos contribuindo para a formação de um mundo de leitores literários e acredito que esse mundo seja mais justo. 


\section{REFERÊNCIAS}

ABRAMOVICH, Fanny. Literatura Infantil: gostosuras e bobices. 5.ed. São Paulo: Scipione, 2003.

ARENA, Dagoberto Buim. Para Ensinar a Ler: Práticas e Tendências. In: MIGUEL, José Carlos; REIS, Martha. Formação Docente- Perspectivas teóricas e práticas pedagógicas. Marília: Oficina Universitária. São Paulo: Cultura Acadêmica, 2015, p. 135-154.

ARENA, Adriana Pastorello Buim; ARENA, Dagoberto Buim. Pais e filhos em dois livros franceses de Literatura Infantil. In Educação, 38 (3): p. 456-465, set.-dez. 2015.

BAJARD, Elie. Ler e dizer. Compreensão do texto escrito. São Paulo: Cortez, 1994.

BAJARD, Elie. Da escuta de textos à leitura. 2.ed. São Paulo: Cortez, 2014.

CANDIDO, Antonio. O direito à literatura. In: Vários Escritos. Rio de Janeiro: Duas Cidades, 2004.

GIROTTO, Cyntia Graziella Guizelim Simões; SOUZA, Renata Junqueira. Estratégias de leitura: para ensinar alunos a compreender o que leem. In: GIROTTO, Cyntia Graziella Guizelim Simões; SOUZA, Renata Junqueira et. al. (org.). Ler e compreender: estratégias de leitura. Campinas: Mercado das Letras, 2010. p 45-114.

GIROTTO, Cyntia Graziella Guizelim Simões Girotto. Literatura na infância: a criança, o livro e a capacidade de ler. Nuançes: estudo sobre a Educação, Presidente Prudente - SP, v 26, p. 34-52, 2015. Disponível em:https://revista.fct.unesp. br/index.php/Nuances/article/viewFile/3745/3146. Acesso em: 03 ago. 2021.

JOLIBERT, Josette et al. Além dos muros da escola: A escrita como ponte entre alunos e comunidade. Tradução de: Ana Maria Netto Machado. Porto Alegre: Artmed, 2006.

LIMA, Elieuza Aparecida; GIROTTO, Cyntia Graziela Guizelim Simões. Leitura e Literatura Infantil: Organização de Espaços, Acervos e Materiais na escola. In: MIGUEL, José Carlos; REIS, Martha. Formação Docente- Perspectivas teóricas e práticas pedagógicas. Marília: Oficina Universitária. São Paulo: Cultura Acadêmica, 2015, p. 47-66. 
MACHADO, Regina. Acordais: Fundamentos teóricos poéticos da arte de contar histórias. São Paulo: DCL, 2004.

MELLO, Suely Amaral. Leitura e literatura na infância. In: GIROTTO, Cyntia Graziella Guizelim Simões; JUNQUEIRA, Simões. Literatura e Educação Infantil: Livros, imagens e práticas de leitura. São Paulo: Mercado das Letras, 2016.

OLIVEIRA, Andreia dos Santos. Encantamento com a literatura infantil: Contribuições à pratica pedagógica para a formação de leitores. 2015. 165f. Dissertação (Mestrado em Educação Escolar)-Universidade Federal de Rondônia, Rondônia, 2015.

OLIVEIRA, Andreia dos Santos; GIROTTO, Cyntia Graziella Guizelim Simões; RODRIGUES, Zélia Inês Lázaro. Uni, duni, tê, o escolhido foi você: seleção de obras literárias na educação infantil. Revista Frontería, V. 1, n. 1, 2020. Disponível em: https://revistas.unila.edu.br/litcomparada/article/view/2348. Acesso em: 24 dez. 2020.

PETIT, Michèle. A arte de ler: ou como resistir à adversidade. Tradução Arthur Bueno e Camila Boldrini. 2. ed. São Paulo: Editora 34, 2010.

PETIT, Michèle. Leituras: do espaço íntimo ao público. Tradução: Celina Olga de Souza. São Paulo: Editora 34, 2013

SISTO, Celso; MOTOYAMA, Juliane. A narração de histórias na infância: Técnicas e Interação. In: GIROTTO, Cyntia Graziella Guizelim Simões; SOUZA, Renata Junqueira (Org.). Literatura e Educação Infantil: Para ler, contar e encantar. Campinas: Mercado das Letras, 2016, p. 111-138. 